\title{
Idosos e Previdência Social: pedidos de auxílio-doença motivados pela depressão do segurado
}

\section{Elderly and Social Security: aid application for disease affected by the depression of the insured}

\author{
Valeska Braga Silva', Newton Luiz Terra², Anelise Crippa ${ }^{3}$ \\ 1 Graduada em Direito pela UNICNEC/Osório. <valeska braga@hotmail.com> \\ ${ }^{2}$ Médico Geriatra. Diretor do Instituto de Geriatria e Gerontologia da PUCRS. Doutor em Gerontologia Biomédica. <terranl@pucrs.br> \\ ${ }^{3}$ Advogada. Professora do curso de Direito da UNICNEC. Doutora em Gerontologia Biomédica. Pós-doutoranda em Direito. <anelise.silva@pucrs.br>
}

\section{ARTICLE INFO}

\section{Article history}

Received: 17/08/2017

Accepted: 06/12/2017

\section{Correspondent Author}

Anelise Crippa

Av. Ipiranga 6681 - Pr. 81, sala 703

90619-900 Porto Alegre, RS, Brasil

<anelise.silva@pucrs.br>

\section{(C) 2017 All rights reserved}

Editors

Alfredo Cataldo Neto

Paula Engroff

\begin{abstract}
RESUMO
No Brasil, por meio de contribuição para a Previdência Social, o trabalhador percebe sustento em casos de velhice, morte, maternidade, doença e invalidez através de auxílios. $\bigcirc$ presente artigo busca respostas acerca da possibilidade da concessão do auxílio-doença por motivo de depressão do segurado da Previdência Social. Para tanto, foi analisado como se dá o direito fundamental à previdência social mediante concessão do benefício devido á essa enfermidade. Inicialmente foi abordado o conceito, o histórico e a previsão legal da Previdência Social. Em um segundo momento foi explorado o benefício em questão, trazendo seu conceito, previsão legal, e requisitos necessários para sua obtenção. Por último, foi feito um estudo sobre a depressão e seus sintomas. $\bigcirc$ artigo em tela possui embasamento em pesquisa bibliográfica e documental, com caráter exploratório e descritivo, mediante a coleta de dados executada por meio de leis, artigos jurídicos, normas, resoluções, jurisprudências, pesquisas on-line, dentre outros que versam sobre o tema. Demonstrou que é possível à concessão do auxílio-doença por motivo depressão, porém, de forma secundária, devendo ficar comprovado a inaptidão total do trabalhador, exigindo-se perícia médica. Conduto, mesmo que em determinados casos seja negado o benefício, não fica evidenciado a afronta à direito fundamental.
\end{abstract}

PALAVRAS-CHAVE: Previdência Social; depressão; ildoso.

\begin{abstract}
In Brazil, by contributing to Social Security, workers are supported in cases of old age, death, maternity, illness and disability through stipends. This article seeks answers about the possibility of granting sick pay due to depression of the Social Security insured. For this purpose, we analyzed how this fundamental right to social security works by granting the benefit on grounds of this illness. Firstly, the concept, history and legal provision of Social Security is addressed. Secondly, the benefit in question is investigated, and its concept, legal provision and requirements needed for getting it are presented. Lastly, a study of depression and its symptoms is conducted. This article is based on bibliographic and documentary research, with an exploratory and descriptive nature, through the collection of data from laws, legal articles, standards, resolutions, jurisprudence, on-line searches, among others dealing with the subject. It was demonstrated that it is possible to grant sick pay for depression, however, on a secondary basis, as the total disability of the worker must be proven and a medical examination is required. Nevertheless, even if in certain cases the benefit is denied, no affront to this fundamental right has been evidenced. KEYWORDS: Social Security; depression; elderly.
\end{abstract}




\section{INTRODUÇÃO}

No Brasil, por meio de contribuição para a Previdência Social, o trabalhador percebe sustento em casos de velhice, morte, maternidade, doença e invalidez através de auxílios. O auxílio-doença, tema deste estudo, é devido aos trabalhadores, segurados da Previdência Social, incapacitados para o exercício de suas atividades laborativas. Este benefício não será devido àquele segurado que, ao filiar-se ao Regime Geral da Previdência Social (RGPS), já apresentava a doença ou lesão alegada como motivo para o requerimento do auxílio, exceto quando a incapacidade é decorrente de desenvolvimento ou agravamento daquela enfermidade.

O ponto de partida para o presente estudo foi a leitura de uma matéria sob título "Aos que sofrem de depressão, condena-se à tristeza. Aquele que sofre de depressão deve escolher entre seu direito de ir em busca de sua felicidade e receber um auxílio-doença? Para o INSS, parece que sim!”. A reportagem em questão relata a história de uma segurada da Previdência Social, que teve seu benefício retirado, devido à publicação de fotos na rede social Facebook. Nas imagens, a beneficiada parecia feliz, e devido a isso, teve seu auxílio suspenso.

Não obstante a depressão ser um assunto importantíssimo, o afastamento do benefício, devido às fotos, afronta o direito de ir em busca da felicidade, assunto pouco discutido no Brasil, mas que encontra-se implícito no princípio da dignidade da pessoa humana, este assegurado no art. 1을 da Constituição Federal. Simples imagens, sorrindo, de um ser humano com esse transtorno, não devem ser reconhecidas como a prova cabal da cura para este mal, mas como um remédio diário e necessário para uma vida melhor.

O estudo é de suma importância uma vez que abrange um transtorno conhecido como o mal do século XXI, pois esta atinge grande parte da população. A depressão está entre os principais transtornos mentais que acometem os idosos.

Em razão do crescimento da expectativa de vida em todo o mundo, tem-se verificado aumento progressivo do número total de idosos na população. Esse fenômeno ocorre de forma ainda mais acelerada nos países em desenvolvimento. Em 1950, havia um total de 204 milhões de idosos no mundo. ${ }^{1}$ Espera-se que em 2030 haja um total de 18,62\% de idosos compondo a população em nosso país. ${ }^{2}$ Em 2050 o Brasil ocupará a sexta colocação em número de idosos no mundo e será ultrapassado somente por China, Índia, Rússia, Estados Unidos e Japão. ${ }^{3}$
Hoje, tem-se as pessoas com 60 anos ou mais (pessoas consideradas idosas no Brasil) ainda, em grande parte das vezes, atuante no mercado de trabalho. A reinserção ou continuidade de labor em nossa sociedade é tão comum que se chegou a debater sobre a desaponsentadoria, matéria que não resultou possível pelos nossos Tribunais. Com o aumento da parcela de idosos em nosso país e sendo esse um dos transtornos que mais incidem nesse percentual da população, faz-se ainda mais necessário o estudo e entendimento da possibilidade do auxílio-doença para idosos com diagnóstico de depressão.

Assim, o objetivo deste artigo é analisar como se dá o direito fundamental à previdência social mediante concessão do auxílio-doença por motivo de depressão. Portanto, esta pesquisa teve por objetivo desvendar o auxílio supracitado, concedido por motivo de depressão, frisando a importância dos direitos fundamentais, em especial para os idosos.

\section{MÉTODO}

Para realização do presente trabalho foi utilizado como metodologia a pesquisa bibliográfica e documental, com caráter exploratório e descritivo, mediante a coleta de dados executada por meio de leis, artigos jurídicos, normas, resoluções, jurisprudências, pesquisas on-line.

A busca jurisprudencial foi realizada através da ferramenta on-line de busca do Tribunal de Justiça do Rio Grande do Sul e do Tribunal Regional Federal da $4^{\underline{a}}$ região. As jurisprudências coletadas tiveram como palavra-chave "auxílio-doença" e "depressão", no período de 2015-2017.

Ressalta-se que o trabalho segue as recomendações éticas da Resolução 510/2016, do Conselho Nacional de Saúde.

\section{PREVIDÊNCIA SOCIAL COMO DIREITO FUNDAMENTAL SOCIAL}

A Previdência Social do Brasil, ao longo de sua existência, passou por diversas alterações, oficializadas por meio de decretos, instruções normativas, e leis. Sérgio Pinto Martins ${ }^{4}$ nos traz um histórico e estabelece que a primeira norma a tratar sobre a Previdência Social foi o Decreto no $4.682 / 23^{5}$, no qual estabeleceu um sistema de benefícios para os ferroviários. Logo mais adiante veio a Lei no $3807 / 60^{6}$, conhecida também como a Lei Orgânica da Previdência Social (LOPS), trazendo a organização da Previdência Social e instituindo benefícios. $\mathrm{Na}$ atualidade, as normas sobre a Previdência estão gravadas nos artigos 201 e 202 da 
Constituição de 1988. Os benefícios são tratados na Lei no 8213/91 e o regulamento é trazido pelo Decreto no 3048/99.?

A Constituição Federal em seu art. $6^{\circ}$, recentemente alterado pela Emenda Constitucional no 90 de 2015, ${ }^{8}$ se refere à Previdência Social como direito social. ${ }^{8}$ Por sua vez, estes se desempenham através da atuação do Estado, para dirimir a desigualdade social.

Dispõe o art. 1ํ da Lei 8.213 que a Previdência Social, sobre contribuição, procura assegurar a seus beneficiários proteção social, viabilizando meios imprescindíveis à sobrevivência do ser humano, devido a sua incapacidade:

Art. 1ํ A Previdência Social, mediante contribuição, tem por fim assegurar aos seus beneficiários meios indispensáveis de manutenção, por motivo de incapacidade, desemprego involuntário, idade avançada, tempo de serviço, encargos familiares e prisão ou morte daqueles de quem dependiam economicamente. ${ }^{9}$

Segundo Sérgio Pinto Martins "previdência vem do latim pré videre, ver com antecipação as contingências sociais e procurar compô-las, ou de praevidentia, prever, antever". ${ }^{4}$ De acordo com Frederico Amado, a previdência social pode ser conhecida tal como um seguro de regime jurídico especial, uma vez que segue normas de Direito Público, obrigatoriamente contributiva, disponibilizando benefícios e serviços aos segurados e seus dependentes, que se diferenciarão conforme plano de cobertura. ${ }^{10}$

A Previdência Social constitui uma forma de propiciar ao trabalhador, auxílios ou serviços na ocasião em que este seja acometido por uma eventualidade social, como desemprego, morte, doença, invalidez, maternidade e velhice.

Antes de tratar do tema propriamente dito, não se pode dispensar a conceituação de Direito Fundamental apresentada por Ingo Wolfgang Sarlet. Para ele, os direitos fundamentais são: "aqueles direitos do ser humano reconhecidos e positivados na esfera do direito constitucional positivo de determinado Estado"11, ou seja, são aqueles direitos reconhecidos pela Constituição que objetivam propiciar condições mínimas para a sobrevivência do ser humano. Ao longo do tempo, tais direitos foram classificados por gerações.

Com o advento da Constituição Federal de 1988, a Previdência Social foi consagrada como Direito Fundamental de segunda geração, uma vez que trata de direitos sociais ${ }^{12}$. $\mathrm{O}$ art. $6^{0}$ da Magna Carta atribuiu a Previdência Social como uma das garantias fundamentais a todos os cidadãos. Como sabido, os benefícios previdenciários servem para garantir meios indispensáveis de manutenção e subsistência aos seus segurados. Por estar diretamente ligada ao princípio da dignidade da pessoa humana, princípio tido como fundamento do Estado democrático de Direito, ${ }^{13}$ a previdência foi reconhecida como tal.

\section{BENEFÍCIO PREVIDENCIÁRIO DE AUXÍLIO-DOENÇA}

A chegada da Emenda Constitucional no 45/2004, ${ }^{14}$ termo inicial da competência material da Justiça do Trabalho para julgar as ações indenizatórias por acidente do trabalho e doenças ocupacionais, trouxe aos operadores do Direito do Trabalho a necessidade de uma maior reflexão a respeito da proteção jurídica à saúde do trabalhador.

O benefício auxílio-doença será percebido em virtude de inaptidão temporária, devendo ser renovável sempre que o segurado dele necessite. Quando se trata da questão do auxílio-doença, é consabido que, ele é devido quando o segurado ficar impossibilitado para o labor, em período superior a quinze dias consecutivos, respeitando sempre a carência exigida, quando esta for necessária. ${ }^{15}$

Lilian Castro de Souza ${ }^{16}$ define que do conceito de auxílio-doença derivam características essenciais para a sua requisição como: qualidade de segurado; período de carência de 12 meses, quando esta for exigida; período de espera de 15 dias para os empregados; exame clínico da incapacidade realizado pela perícia médica da Previdência Social, renovável periodicamente.

Este amparo provido ao segurado é provisório, o critério para estabelecer o tempo que irá perdurar é a certeza de reabilitação do beneficiado, conjuntamente com o retorno a seu trabalho. O critério acima citado é estabelecido mediante perícia médica. É válido frisar que este provento não será concedido se o beneficiário, ao se tornar segurado, já for possuidor da doença ou da lesão, motivo pelo qual sugeriu o benefício, exceto quando sobrevier a incapacidade por agravamento das mesmas.

Quanto a sua previsão legal, o benefício denominado auxílio-doença está assegurado constitucionalmente como benefício integrante da Previdência Social, conforme designa a Magna Carta:

Art. 201. A previdência social será organizada sob a forma de regime geral, de caráter contributivo e de filiação obrigatória, observados critérios que preservem o equilíbrio financeiro e atuarial, e atenderá, nos termos da lei, a:

I - cobertura dos eventos de doença, invalidez, morte e idade avançada. ${ }^{8}$ 
Contudo, esse dispositivo teve sua regulamentação na Lei Federal no 8213/91, que dispõe sobre os Planos de Benefícios da Previdência Social, discorrendo sobre o auxílio-doença:

\begin{abstract}
Art. 59. O auxílio-doença será devido ao segurado que, havendo cumprido, quando for o caso, o período de carência exigido nesta Lei, ficar incapacitado para o seu trabalho ou para a sua atividade habitual por mais de 15 (quinze) dias consecutivos. Parágrafo único. Não será devido auxílio-doença ao segurado que se filiar ao Regime Geral de Previdência Social já portador da doença ou da lesão invocada como causa para o benefício, salvo quando a incapacidade sobrevier por motivo de progressão ou agravamento dessa doença ou lesão. ${ }^{9}$
\end{abstract}

O período de carência, "é o número mínimo de contribuições mensais indispensáveis para que o beneficiário faça jus ao benefício, consideradas a partir do transcurso do primeiro dia dos meses de suas competências", 9 em versão própria do art. 24 da referida Lei. Neste caso, o período mínimo exigido, é de 12 meses. Cabe salientar, em caso de acidente de qualquer natureza, ou de doença profissional, não será exigido este período mínimo de contribuição para a Previdência Social. Ademais, a Lei em comento, compreende em seu dispositivo, um rol de doenças em que não é exigido a carência:

Art. 151. Até que seja elaborada a lista de doenças mencionada no inciso II do art. 26, independe de carência a concessão de auxílio-doença e de aposentadoria por invalidez ao segurado que, após filiar-se ao RGPS, for acometido das seguintes doenças: tuberculose ativa, hanseníase, alienação mental, esclerose múltipla, hepatopatia grave, neoplasia maligna, cegueira, paralisia irreversível e incapacitante, cardiopatia grave, doença de Parkinson, espondiloartrose anquilosante, nefropatia grave, estado avançado da doença de Paget (osteíte deformante), síndrome da deficiência imunológica adquirida (AIDS) ou contaminação por radiação, com base em conclusão da medicina especializada. ${ }^{9}$

Disponibilizado o auxílio, o segurado passa a receber uma parcela de 91\% do salário benefício, como forma de compensar a sua contribuição previdenciária, uma vez que não receberá contribuição durante o período que estiver em gozo do benefício, assim expressa o art. 61 da Lei 8213/91. Extingui-se a concessão do benefício com a recuperação do segurado. Contudo, estabelece o artigo 62 da Lei de Planos e Benefícios:

O segurado em gozo de auxílio-doença, insusceptível de recuperação para sua atividade habitual, deverá submeter-se a processo de reabilitação profissional para o exercício de outra função. Não será suspenso o benefício até que o segurado seja considerado reabilitado para o desempenho de atividade que the garanta a subsistência ou, quando considerado não recuperável, for aposentado por invalidez. ${ }^{9}$

Ademais, o auxílio será extinto de quatro formas diferentes: através da reabilitação do segurado; quando irrecuperável o seu estado incapacitante e a ele for convertido o auxílio em aposentadoria por invalidez; habilitação do trabalhador para desempenhar outra função que lhe garanta subsistência, e por fim, a conversão em aposentadoria por idade, desde que esta seja solicitada pelo segurado, e que seja observada a carência.

\section{DEPRESSÃO}

Com a chegada da Emenda 45, e consequentemente com a preocupação quanto à proteção jurídica da saúde dos trabalhadores, passou-se a ser analisada a possibilidade de se caracterizar tecnicamente a depressão como "doença" do trabalho, procurando delimitar até que ponto esta enfermidade e o trabalho interferem um no outro. A realidade do nosso país mostra a questão da atividade laboral em pessoas com 60 anos ou mais. Essa parcela populacional é a mais atingida pela depressão, podendo dificultar a continuação da atividade produtiva.

Com o envelhecimento populacional, verificam-se mudanças nas principais causas de morbidade e mortalidade, de tal modo que as doenças não transmissíveis e as causas externas passam a predominar sobre as doenças transmissíveis, pois à medida que os indivíduos envelhecem, aumenta o risco de que elas adquiram doenças crônicas e desenvolvam incapacidades, acarretando importante sobrecarga aos sistemas de saúde e previdenciário. Dentre as principais doenças que acometem os idosos estão os transtornos mentais dos quais a depressão faz parte. Por diversos motivos, a depressão na velhice tem sido pouco diagnosticada e tratada. Essa é uma situação grave em termos de saúde pública, pois a depressão causa importante piora na qualidade de vida, incapacidade e eleva a morbidade e mortalidade. Dados recentes sugerem que o índice de suicídio entre pessoas idosas está crescendo nos últimos anos no Brasil. A Organização Mundial da Saúde estima que, em 2020 a depressão será a segunda causa de incapacidade no mundo. ${ }^{17,18,19}$

A descrição sobre o transtorno depressivo é algo desafiador, tanto para clínicos quanto para pesquisadores e estudiosos. A enfermidade conhecida como o mal do século, é uma doença do corpo e da 
mente. A natureza exata dela varia de pessoa para pessoa, e resulta da combinação de fatores ambientais, psicológicos, e genéticos. ${ }^{20}$

Assim descreve Urania Tourinho Peres sobre a melancolia, esta que deu lugar a depressão "o que dizer da dor que não pode ser dita? Sem causa ou natureza definíveis, sem possibilidade de compreensão? Dor do nada, simplesmente do vazio de existir, indescritível, incomensurável (...)"21.

A depressão é um distúrbio mental caracterizado por tristeza profunda, e perda do interesse de viver, lesando negativamente o emprego, as relações familiares, as refeições, o sono, e principalmente, a saúde em geral. Como já citado, este transtorno, não tem causa específica, mas destacam-se alguns aspectos ameaçadores como: modificação expressiva na vida, história de depressão na família, problemas de saúde crônicos e consumo de drogas. ${ }^{22}$

Neste sentido, o autor Andrew Salomon ${ }^{23}$ intitula a depressão como a imperfeição no amor, e para poder amar, temos que ser capazes de nos desesperarmos ante as perdas, assim a depressão seria o mecanismo desse desespero. Na lição de José Alberto Del Porto ${ }^{24}$, o termo depressão pode ser utilizado para intitular tanto um estado afetivo, quanto um sintoma, uma síndrome, ou uma doença. Na qualidade de sintoma, esta pode surgir como transtorno de estresse pós-traumático, demência, esquizofrenia, alcoolismo, ou doenças clínicas.

Enquanto síndrome, ela apresenta alterações do humor como a tristeza, a irritabilidade, a falta da capacidade de sentir prazer, e apatia. Por fim, como doença, a depressão tem sido vista como transtorno depressivo maior, melancolia, distimia, e depressão integrante do transtorno bipolar. Para tanto, depressão consiste em um distúrbio psicológico afetivo, causado por uma tristeza profunda, que impossibilita o ser humano de querer viver, "é um sentimento da morte estando vivo, uma fraqueza do ser, um desencanto absoluto". ${ }^{21}$

Como ficou evidenciado, em relação ao transtorno aqui estudado, não se pode separar o conceito de seus sintomas, pois um complementa o outro. Para caracterizar a depressão é necessário citar seus sintomas, pois é a presença deles, por período superior a duas semanas, que se tem o diagnóstico desta doença, caso contrário, a pessoa estará passando por um estado afetivo que logo passará.

De acordo com José Alberto Del Porto ${ }^{24}$, podese dividir esses sintomas em psíquicos, fisiológicos, e comportamentais. Os psíquicos baseiam-se em sensação de tristeza, sentimentos de culpa, apatia, desesperança, fadiga ou perda de energia para as atividades cotidianas, diminuição da capacidade de pensar, de se concentrar, e de tomar decisões. Os fisiológicos ocasionam a alteração do sono, podendo causar insônia ou hipersonolência, alterações do apetite e consequentemente perda ou ganho excessivo de peso, e redução do interesse sexual. Já os sintomas comportamentais, caracterizam-se no retraimento social, crises de choro, e comportamentos suicidas.

Ressalta-se que de pessoa para pessoa este transtorno se manifesta de forma diferente, uma vez que existem variações desse mal que assombra a sociedade.

\section{ANÁLISE JURISPRUDENCIAL SOBRE CONCESSÃO DO AUXÍLIO-DOENÇA PARA SEGURADO EM RAZÃO DA DOENÇA DE DEPRESSÃO}

A fim de uma melhor compreensão do tema abordado se faz necessário a análise de casos concretos sobre a concessão do benefício auxílio-doença. Para tanto, examinar-se-á jurisprudências do Tribunal de Justiça do Rio Grande do Sul (TJRS), e Tribunal Regional Federal da 4을 Região (TRF4). Foram encontradas 17 decisões judiciais no TJRS e 1.658 no TRF4, que tinham relação com pedidos de auxíliodoença e depressão, no período de 2015 até outubro de 2017. O crescimento dos pedidos que envolvem depressão é possível ser identificado na Tabela 1 .

Tabela 1. Recursos apresentados no site do Tribunal de Justiça do Rio Grande do Sul (TJRS) e no Tribunal Regional Federal (TRF4) envolvendo o auxílio-doença e a depressão.

\begin{tabular}{ccc}
\hline Ano & Tribunal & Total de Decisões \\
\multirow{2}{*}{2017} & TJRS & 9 \\
& TRF4 & 494 \\
2016 & TJRS & 6 \\
& TRF4 & 575 \\
2015 & TJRS & 2 \\
& TRF4 & 589 \\
\hline
\end{tabular}

O Tribunal de Justiça do Estado do Rio Grande do Sul é órgão do Poder Judiciário, com jurisdição em todo o território estadual, e possui sede em Porto Alegre. Ademais, cabe salientar, que este Tribunal julga, em grau de recurso, matéria cível e penal de sua competência. ${ }^{25}$

Desse modo, segue análise de decisões deste Tribunal.

REEXAME NECESSÁRIO. PREVIDENCIÁRIO. ACIDENTE DE TRABALHO. AUXÍLIO. DOENÇA. DEPRESSÃO. TRANSTORNO DE ADAPTAÇÃO. INCAPACIDADE TEMPORÁRIA. 1. Consoante se depreende da redação do 
art. 59, da Lei n. 8.213/91, "o auxílio-doença será devido ao segurado que, havendo cumprido, quando for o caso, o período de carência exigido nesta Lei, ficar incapacitado para o seu trabalho ou para a sua atividade habitual por mais de 15 (quinze) dias consecutivos". Caso concreto em que configurados os pressupostos legais à concessão do auxílio-doença. 2. Benefício devido desde o indevido cancelamento administrativo do anterior auxílio-doença acidentário. 3. Com o advento da Lei $\mathrm{n}^{\mathrm{o}}$ 11.960, de 2009, a partir de 29-06-2009, a correção monetária e os juros moratórios deverão corresponder aos índices oficiais de remuneração básica e juros aplicados à caderneta de poupança (art. 5으. 4 . Em relação às custas processuais, em face da nova redação do art. 11 do Regimento de Custas (Lei 8.121/85), dada pela Lei 13.471/10, está isento o INSS de seu pagamento. 5. Vão mantidos os honorários advocatícios fixados, devendo o INSS arcará com honorários de 10\% sobre o valor das prestações vencidas até a sentença. SENTENÇA MANTIDA EM REEXAME NECESSÁRIO. ${ }^{26}$

Como bem elucida a decisão, há casos em que é exigido um período de carência. Lilian Castro de Souza acredita que se trata de um período breve, uma vez que são exigidas apenas 12 contribuições mensais. Ainda neste sentido, a autora, ressalta que há casos em que o período não é exigido, ocorrendo quando o segurado é portador de uma das moléstias descritas no art. 151 da Lei 8213/91, ou quando ocorre um acidente de trabalho. Ademais, exigir carência nestas hipóteses acarretaria na destruição da finalidade protetiva primordial da Previdência Social. ${ }^{16}$

APELAÇÃO CÍVEL. PREVIDENCIÁRIO. ACIDENTE DE TRABALHO. AUXÍLIO-DOENÇA. BURSITE. SÍNDROME DO TÚNEL DO CARO. DEPRESSÃO. TEMPORARIEDADE DA INCAPACIDADE. 1. Consoante se depreende da redação do art. 59, da Lei n.o 8.213/91, "o auxílio-doença será devido ao segurado que, havendo cumprido, quando for o caso, o período de carência exigido nesta Lei, ficar incapacitado para o seu trabalho ou para a sua atividade habitual por mais de 15 (quinze) dias consecutivos". Caso concreto em que configurados os pressupostos legais à concessão do auxíliodoença, inclusive com nexo causal relativamente à atividade antes desempenhada. Benefício devido desde o cancelamento administrativo. 2. Com o advento da Lei no 11.960, de 2009, a partir de 29. 06-2009, a correção monetária e os juros moratórios deverão corresponder aos índices oficiais de remuneração básica e juros aplicados à caderneta de poupança (art. 50). 3. Em relação às custas processuais, em face da nova redação do art. 11 do Regimento de Custas (Lei 8.121/85), dada pela Lei 13.471/10, está isento o INSS de seu pagamento. 4. Honorários advocatícios fixados em 10\% sobre o valor da condenação, incidindo apenas sobre as parcelas vencidas até a data da condenação, ou seja, do acórdão neste caso, conforme inteligência da Súmula 111 do STJ. APELO PROVIDO. ${ }^{27}$

Conforme referido no julgado acima, é necessário que se cumpra alguns requisitos para que o benefício seja concedido. De acordo com Marina Vasques Duarte, são dois os requisitos: incapacidade para o trabalho ou atividade habitual por mais de 15 dias consecutivos e a carência. A primeira trata, em regra, de uma incapacidade temporária, que impede o segurado de exercer suas atividades laborativas. A segunda trata do período que se exige de contribuição à Previdência Social para fazer jus ao benefício. ${ }^{28}$

APELAÇÃO. REEXAME NECESSÁRIO. ACIDENTE DO TRABALHO. AUXILIO-DOENÇA. PREVISÃO CONSTITUCIONAL DA PROTEÇÃO AO TRABALHADOR. EXAME DA LEGISLAÇÃO. AMPUTAÇÃO DE FALANGE DE QUIRODÁCTILO. TRANSTORNOS PSIQUIÂTRICOS (DEPRESSÃO) DECORRENTE DA LESÃO. CONCAUSA. INCAPACIDADE TEMPORÁRIA. - AUXÍlIO-DOENÇA - Os benefícios acidentários estão inseridos no sistema constitucional de proteção ao trabalhador, constituindo-se em direito social fundamental. Compreensão do princípio constitucional da dignidade humana (art. 1ํㅡㄴ III, CF) e do artigo 6o da Constituição Federal. Os requisitos legais do auxílio-doença estão previstos no artigo 59 da Lei $\mathrm{n}$ - 8.213/91. A presença da incapacidade para o trabalho por período superior a 15 (quinze) dias é requisito fundamental para a concessão do benefício, a ser constatada mediante a realização de prova pericial. A incapacidade laboral, comprovada por pericia médica, por período superior a 15 (quinze) dias autoriza a concessão ao trabalhador do auxílio-doença. Precedentes. Caso em que a perícia produzida nos autos demonstra que o autor se encontra temporariamente incapacitado para o trabalho, por estar acometido de quadro depressivo, decorrente da lesão sofrida no acidente de trabalho, que resultou a amputação de falange do 4 o quirodáctilo da mão direita. Acidente que atuou como causa para o desencadeamento da depressão. - TERMO INICIAL - Demonstrada a persistência da incapacidade da parte autora após o cancelamento administrativo, o termo inicial do benefício deve observar tal marco temporal. - CORREÇÃO MONETÁRIA - A correção monetária incidente sobre as parcelas vencidas será pelo IGP-DI até 31.03.2006, e o INPC desde 01.04.2006 até a vigência da Lei $\mathrm{n}$ o 11.960/09, quando tanto a correção monetária quanto os juros moratórios serão atualizados uma única vez e pelos índices oficiais de remuneração básica e juros aplicados à caderneta de poupança. - CUSTAS ISENÇÃO - As Pessoas Jurídicas de Direito Público estão isentas do pagamento de custas processuais, 
despesas e emolumentos, conforme o previsto no art. $1^{\text {o }}$ da Lei n⿳⺈ 13.471/2010, que deu nova redação ao art. 11 do Regimento de Custas (Lei no 8.121/85). HONORÁRIOS ADVOCATÍCIOS - Tratando-se de ação buscando a concessão de benefícios previdenciários, o entendimento consolidado nesta Câmara é de que a verba honorária seja fixada em $10 \%$ sobre as parcelas vencidas até a prolação da sentença, nos termos da Súmula 111 do STJ. APELO DO AUTOR PROVIDO. APELO DO INSS PARCIALMENTE PROVIDO. SENTENÇA PARCIALMENTE MODIFICADA EM REEXAME NECESSÁRIO. ${ }^{29}$

Em concordância com a decisão supracitada, Sérgio Pinto Martins estabelece que o termo inicial do direito ao referido benefício, se dá a partir do $16^{\mathrm{O}}$ dia de afastamento do empregado de suas atividades. Se o mesmo estiver afastado por um período superior a 30 dias, contar-se-á da data do requerimento. Mas para os demais segurados, o início começa a contar da data em que se inicia a incapacidade, perdurando até a sua cessação. ${ }^{4}$

O Tribunal Regional Federal da 4⿳亠丷a Região, com sede em Porto Alegre, tem jurisdição nos Estados do Paraná, Santa Catarina e Rio Grande do Sul. Neste Tribunal os magistrados julgam recursos de ações que abarcam empresas públicas autarquias e a União Federal, assim como causas envolvendo matéria previdenciária e execuções fiscais. ${ }^{30}$ Desse modo, segue análise de decisões do Tribunal.

\section{AGRAVO DE INSTRUMENTO. PROCESSO CIVIL. PREVIDENCIÁRIO. BENEFÍCIO POR INCAPACIDADE. COMPLEMENTAÇÃO DA PROVA PERICIAL. DESNECESSIDADE. 1. Tendo o expert respondido de modo claro e coerente a todos os quesitos formulados, sendo conclusivo quanto ao atual estado de saúde da parte requerente, bem como quanto aos períodos em que constatou a existência de incapacidade laborativa, inexiste motivo a ensejar a complementação da prova pericial. 2. O julgador formará sua convicção não apenas com base na prova pericial, mas sim a partir da composição dos dados por ela fornecidos com os demais elementos constantes dos autos. 3. A mera irresignação da parte com as conclusões do perito não fundamenta, isoladamente, pedido de nova perícia médica ou sua complementação, quando a matéria se encontra suficientemente e escla- recida. ${ }^{31}$}

Diante do exposto, trata-se de agravo de instrumento interposto com o objetivo de restabelecimento do benefício de auxílio-doença, mediante complementação da prova pericial. No caso em questão, a perita respondeu de modo claro e coerente a todos os quesitos formulados, sendo conclusiva quanto ao atual estado de saúde do requerente, no qual se encontra em condições para trabalhar, sendo assim indeferido o agravo. Ressalte-se que a produção probatória tem como destinatário final o juiz da causa, cabendo a ele avaliar a necessidade de nova perícia. A mera discordância da parte não fundamenta a realização de nova perícia, quando esta estiver de fato esclarecida.

Segundo Ivan Kertzman, o INSS poderá determinar, mediante perícia de expert, o prazo que entender razoável para a recuperação da capacidade para o trabalho do segurado, não sendo obrigatória a realização de nova perícia. ${ }^{32}$

\begin{abstract}
AUXÍLIO-DOENÇA. RESTABELECIMENTO. INCAPACIDADE TEMPORÁRIA. TERMO INICIAL. DATA DA CESSAÇÃO.

Comprovada a incapacidade temporária para o exercício das atividades laborativas habituais, é cabível o restabelecimento de auxílio-doença, devendo-se reconhecer efeitos financeiros retroativos à data da indevida cessação do benefício, quando demonstrado pela análise dos elementos dos autos que, embora descoberto do amparo previdenciário, o segurado permaneceu incapacitado. ${ }^{33}$
\end{abstract}

No caso em análise, trata-se de segurado especial da previdência social, portador de transtorno bipolar e depressão, constatado mediante perícia do INSS. Deram provimento ao restabelecimento do auxílio desde a data da indevida cessação. O juízo monocrático fundamentou sua decisão de acordo com o laudo médico, uma vez que ficou determinado por mais dois anos a concessão do benefício, levou em consideração também que o autor ficou em gozo deste por mais de um ano como segurado especial, trabalhador rural, pela mesma doença diagnosticada na perícia judicial. Contudo, concluiu que se tratava de doença em estado complicado, devendo assim ser restabelecido o benefício.

\section{AGRAVO DE INSTRUMENTO. PREVIDEN- CIÁRIO. AUXÍLIO-DOENÇA. INCAPACI- DADE DE NATUREZA PSÍQUICA. PROVA PERICIAL. MÉDICO ESPECIALISTA NA ÁREA. Demonstrada a pertinência da alegação de incapacidade laboral em virtude de moléstias de natureza psíquicas, justificável a complementação da instrução probatória mediante realização de perícia com especialista em psiquiatria. Precedentes desta Corte..$^{34}$}

A decisão em questão trata-se de agravo de instrumento impetrado com o objetivo de garantir prova pericial de médico especialista na área psiquiátrica, uma vez que na decisão de primeiro grau, mediante perícia de infectologista, esta se delimitou a verificar 
a incapacidade, exclusivamente física, em decorrência da doença HIV. Sobretudo, desde o início a segurada faz menção a transtornos psicológicos decorrentes do diagnóstico de HIV, e não houve nenhuma alegação nesse sentido.

Desta forma, se faz necessário a avaliação da condição psíquica de profissional especialista em psiquiatria. Assim decidiu acertadamente o juízo em segundo grau dando provimento ao agravo de instrumento, deferindo a antecipação dos efeitos da tutela recursal para autorizar a realização de nova prova pericial por médico psiquiatra.

Conclui-se que dessa maneira a previdência social cumpre o seu papel de proteger e garantir meios imprescindíveis á sobrevivência do ser humano acometido por alguma eventualidade, como assim descreve o art. $1^{\circ}$ da Lei 8213/91.

\section{CONSIDERAÇÕES FINAIS}

No Estado brasileiro, por meio de contribuição para a Previdência Social, o trabalhador percebe sustento em casos de velhice, morte, maternidade, doença e invalidez através de auxílios. Como sabido, os benefícios previdenciários servem para garantir meios indispensáveis de manutenção e subsistência aos seus segurados, e por a Previdência estar diretamente ligada ao princípio da dignidade da pessoa humana, esta foi reconhecida como tal. Para tanto, o benefício denominado auxílio-doença está assegurado constitucionalmente como benefício integrante da Previdência Social.

O direito fundamental à Previdência, mediante concessão do auxílio-doença por motivo de depressão, necessita de alguns requisitos para ser concretizado. Para que se possa ser agraciado com o benefício é indispensável que a pessoa seja segurada da previdência social, respeite a carência quando esta for necessária, e mediante perícia médica estabelecida por perito do INSS, fique comprovada inaptidão para o labor, seja ela temporária ou definitiva, onde neste caso, poderá ser transformado o benefício em aposentadoria por invalidez.

No estudo em questão, abordou-se a depressão, esta por sua vez é um transtorno mental caracterizado pela tristeza profunda, e perda do interesse de viver, lesando negativamente o emprego, as relações familiares, as refeições, o sono, e principalmente, a saúde em geral. Quando esta enfermidade tiver como origem o ambiente de trabalho, desde que fique comprovado o seu estado grave, se faz necessário o afastamento do segurado para recebimento de auxílio por incapacidade decorrente da sua atividade profissional.
Percebe-se que nas decisões não fica demonstrado à afronta ao direito fundamental embora, em muitos casos, seja negado o benefício ao segurado, devido ao fato de não ficar comprovado à incapacidade para o trabalho. Como as pessoas, muitas vezes, agem de má-fé e querem ser beneficiados com o auxílio-doença por considerá-lo uma renda extra e fácil, cada vez mais o INSS tem sido rígido ao fazer a concessão do benefício.

Ademais fica evidenciado que o auxílio-doença quando concedido por motivo de depressão, esta não seria a principal razão, mas sim por outras doenças que incapacitam o trabalhador conjuntamente com esta enfermidade. Portanto, é imprescindível que a depressão seja reconhecida como transtorno mental incapacitante para o desenvolvimento da atividade profissional, pois se trata de uma enfermidade gravíssima que atinge, cada vez de forma mais frequente, a população.

\section{REFERÊNCIAS}

1. Brasil. Instituto Brasileiro de Geografia e Estatística (IBGE). Censo Demográfico 2010.

2. Brasil. Instituto Brasileiro de Geografia e Estatística (IBGE). Projeção da população do Brasil e das Unidades da Federação. 2015.

3. Terra N. Prefácio. In: Moriguchi Y, Terra N, Bós AJG, Scnheider RH, Schwanke CHA, de Carli GA, et al., editors. Entendendo as síndromes geriátricas. Porto Alegre: Edipucrs; 2013. p. 7-8.

4. Martins SP. Direito da Seguridade Social. 26 $6^{\mathrm{a}}$ ed. São Paulo: Saraiva, 2016

5. Brasil. Decreto no 4.682, de 24 de janeiro de 1923. Cria, em cada uma das empresas de estradas de ferro existentes no país, uma caixa de aposentadoria e pensões para os respectivos empregados.

6. Brasil. Lei no 3.807, de 26 de agosto de 1960. Dispõe sobre a Lei Orgânica da Previdência Social.

7. Brasil. Decreto no 3048, de 06 de maio de 1999. Regulamento da Previdência Social.

8. Brasil. Constituição da Republica Federativa do Brasil de 1988.

9. Brasil. Lei no 8213, de 24 de julho de 1991. Lei que dispõe sobre os Planos de Benefícios da Previdência Social.

10. Amaro F. Direito Previdenciário. 7ª ed. Salvador: JusPodivm; 2016.

11. Sarlet IW. A Eficácia dos Direitos Fundamentais. 10aㅡ ed. Porto Alegre: Livraria do Advogado; 2010.

12. Mellos NB. A Previdência Social como Direito Fundamental. Páginas de Direito. 2014.

13. Sarlet IW. Dignidade da Pessoa Humana e Direitos Fundamentais na Constituição Federal de 1988. Porto Alegre: Livraria do Advogado; 2006.

14. Brasil. Constituição de 1988. Emenda Constitucional no 45, de 30 de dezembro de 2004. Altera dispositivos dos arts. 5', 36, 52, 92, 93, 95, 98, 99, 102, 103, 104, 105, 107, 109, $111,112,114,115,125,126,127,128,129,134$ e 168 da Constituição Federal, e acr. 
15. Oliveira A de. Manual Prático da Previdência Social. 11aㅡ ed. São Paulo, Atlas; 2003.

16. Souza LC de. SOUZA, Lilian Castro de. Direito Previdenciário. 7ª ed. São Paulo: Atlas; 2012.

17. Terra N, Moriguchi, Y. Moriguchi, E, Werle. B, Barcelos, L, Nascimento, E, Diogo, C, Bonardi, G, Flores, G, Haas M. Geriatria Moderna para Leigos. Leitura XXI; 2007.

18. Moreno, D, Moreno, R, Nardi A. Depressão. Master's Meeting. 2009.

19. Stopper A. Depressão em idosos. Guia para diagnóstico e conduta. Leitura Médica; 2015.

20. Hospital Israelita Albert Einstein. Guia de saúde familiar: depressão Domingo. São Paulo: Ed. Três.

21. Peres UT. Depressão e Melancolia. 3a ed. Rio de Janeiro: Zahar; 2010.

22. Lafer B. Depressão no Ciclo da Vida. Porto Alegre: ArtMed; 2000.

23. Solomon A. O Demônio do Meio-Dia: Uma Anatomia da Depressão. 2a $\underline{a}$ ed. São Paulo: Companhia das Letras; 2014.

24. Del Porto JA. Conceito e diagnóstico. Rev Bras Psiquiatr [Internet]. 1999 maio;21 (supl 1):06-11. Disponível em: http://www.scielo.br/scielo.php?script $=$ sci_arttext\&pid $=$ S1516-44461999000500003\&lng = pt\&tlng=pt

25. Rio Grande do Sul. Poder Judiciário. Tribunal de Justiça do Rio Grande do Sul. Sede e Competência do TJRS. [Acesso em 29 out. 2016]. Disponível em: http://www.tjrs.jus.br

26. Rio Grande do Sul. Tribunal de Justiça. Nona Câmara Civil. Reexame Necessário nํㅜ 70053113593 - Comarca de Caxias do Sul. Relator: Marilene Bonzanini, 06 de mar. 2013. Diário de Justiça, Porto Alegre, 23 de mar. 2013.

27. Rio Grande do Sul. Tribunal de Justiça. Nona Câmara Civil. Apelação Civil no 70049447402 - Comarca de Getúlio Vargas. Relator: Leonel Pires Ohlweiler, 30 de maio 2012. Diário de Justiça, Porto Alegre, 15 de jun. 2012.

28. Duarte MV. Direito Previdenciário. 7ª ed. Porto Alegre: Jurídico V; 2011.

29. Rio Grande do Sul. Tribunal de Justiça. Nona Câmara Civil. Apelação Civil no 70051261683 - Comarca de Vacaria. Relator: Marilene Bonzanini, 14 de nov. 2012. Diário de Justiça, Porto Alegre, 27 de nov. 2012.

30. Brasil. Tribunal Regional Federal da $4^{\mathrm{a}}$ Região. Competência e Organização do TRF da 4⿳亠丷厂 Região. Disponível em: http:// www2.trf4.jus.br/trf4/controlador.php?acao = pagina visualizar\&id_pagina $=1$

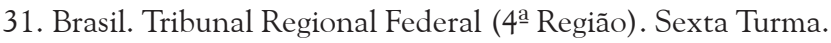
Agravo de Instrumento $\mathrm{n}^{\mathrm{o}}$ 5028190-11.2015.4.04.0000, Relator: Vânia Hack de Almeida. 21 de out. 2015. Diário Eletrônico, 22 de out. 2015.

32. Kertzman I. Curso prático de direito previdenciário. 12ª ed. Salvador: JusPodivm; 2015.

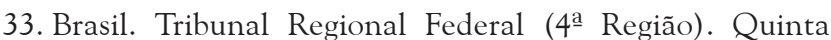
Turma. Apelação/Reexame Necessário no 0021253 . 80.2014.404.9999, Relator: Taís Schilling Ferraz. 03 maio 2016. Diário Eletrônico, 17 maio 2016.

34. Brasil. Tribunal Regional Federal (4a Região). Quinta Turma. Agravo de Instrumento $\mathrm{n}^{\mathrm{o}}$ 5042416-21.2015.4.04.0000, Relator: Rogério Favreto. 16 fev. 2016. Diário Eletrônico, 02 mar. 2016. 